\title{
Policies of Safety and Autonomous Regulation: The Case of a Uruguayan Paper Company
}

\author{
Francisco Pucci \\ Departamento de Sociología, Facultad de Ciencias Sociales, Universidad de la República, Montevideo, Uruguay \\ Email: francisco.pucci@cienciassociales.edu.uy
}

How to cite this paper: Pucci, F. (2016) Policies of Safety and Autonomous Regulation: The Case of a Uruguayan Paper Company. Open Journal of Safety Science and Technology, 6, 55-69. http://dx.doi.org/10.4236/ojsst.2016.63005

Received: July 28, 2016

Accepted: October 22, 2016

Published: October 25, 2016

Copyright $\odot 2016$ by author and Scientific Research Publishing Inc. This work is licensed under the Creative Commons Attribution International License (CC BY 4.0)

http://creativecommons.org/licenses/by/4.0/

\begin{abstract}
The study analyzes the processes of autonomous regulation of the risk concerning the production of paper in a first line company in Uruguay. The dominant culture of security in this business is based on the knowledge of the trade, composed by a set of implicit rules governing the formation and transmission of knowledge. This culture of trade implies that the standards of protection of the workers from occupational hazards are neither imposed by management nor by the headquarters, but constructed in the daily interaction among the workers. In the context of the difficulties met in order to build a joint regulation of security between the management of the company and the Union, the knowledge and experience of the workers appear as the source of more effective safety regulation. However, this autonomous management is crossed by inter-generational and sectors tensions and contradictions, preventing the construction of a labor reflectivity on this theme. In this enclave, the Union loses capacity for action in terms of demands aimed at preventive and reactive security since it is focused on negotiating the impacts of new policies of labor and employment on the company management. There is also a low level of reflectivity from the workers in relation to the components of their culture of trade. Although it actually operates, it is not stated by the collective, and even less recognized as such in the framework of tension and competition between sectors and work teams.
\end{abstract}

\section{Keywords}

Work, Security Regulation, Paper, Industry

\section{Introduction}

Risk management in organizations is articulated substantively with the management of the implemented human resources. Security policies and decisions related to it, though possessing a technical scientific component, they also have a social and political com- 
ponent which is based on the idea that there are formal and/or informal processes of risk selection which depend on multiple factors: the characteristics of the production process, the formation of the workforce and the organizational culture. In this regard, risk management involves coordination with global processes of human resource management, underpinned by changes in work routines and everyday behavior of labor actors.

In this paper, we aimed at analyzing the link between risk management processes and human resources management in a Uruguayan paper company, with reference to the related processes of self regulation and control regulation. To achieve these goals, we will perform the following steps: 1) development of the theoretical framework from where the processes of risk management are analyzed; 2) presentation of the research methodology; 3) characterization in broad terms of policies for managing human resources implemented by the company; 4) description of the security policies implemented; 5) analysis of the processes of self-regulation implemented by labor collectives.

The aim of this work is to show that the implementation of security models cannot be understood only as a rational and technical process: factors such as the legitimacy of controls, social relations between different occupational classes and tacit knowledge of workers are crucial to understand the actual functioning of risk management processes in organizations.

\section{1) Management and regulation of risk}

Amalberti (2013) [1] defines security of complex systems as the result of the sum of two entities: the security derived from the rules and procedures (regulated safety), and from the operators skills and system professionals (managed security). Very safe systems have numerous procedures and prohibitions. Security level is high, but the adaptability of its operators is very limited, since they are not exposed to risky situations and, therefore, lack the necessary training to work outside the procedural framework. An example of this type of system is aviation where pilots must follow strict procedures and regulations with no room for experimentation at risk.

Artisanal models, on the other hand, mean that operators are exposed to risk in a context of weak institutional regulation: total security is quite modest and basically depends on the qualities and skills of the operators, so we must take into account the strong variations inherent therein. Nevertheless, these experts' ability to adapt to the fortuitous conditions is remarkable and is part of their daily lives. A classic example of this type of system is the hospital where patients' safety depends largely on the professional skills of doctors.

In this sense, Amalberti argues that the idea of a single model applicable to all the security systems is innocent. Security is a social construction that adapts to the demand. There are several possible answers that generate different security models, which have their own logic of operation, their advantages and their limits. These models differ from each other depending on the balance between the level of security and of adaptability

The first solution is to eliminate exposure to risks.

- The second solution is to accept exposure accepting the rules and procedures. 
- The third solution is to accept risk exposure under unregulated conditions.

From these three premises three models of security are deducted.

The model of ultra-safe systems: requires equivalent, interchangeable operators. But supervisory qualities are the ones that will prevent these operators to be exposed to the most fortuitous risks, limiting such exposure to a finite list of failures and difficulties.

HRO model: risks should be managed on a daily basis although the main objective is to control them and not to be exposed to them. Security depends on the group, organization, roles and responsibilities of each one. The model analyzes its failures and tries to understand their causes. High reliability organizations combine risk exposure rules with labor collective internalized and legitimized procedures by the labor collective procedures.

The resilient model seeking exposure to risk is the very essence of the model. Security is associated to win, to survive, and only the winners through their stories transmit their knowledge about safety.

This tension between regulation and autonomy defines the processes of social construction of risk in organizations. From a sociological perspective, the focus of the "conquest of security" seems associated with ultra-safe models (Dourlens et al., 1991) [2] supported by mechanical concepts of security: the sum of measures of partial security increases the overall safety of systems, or the idea that a system is reduced to a linear chain of components whose reliability is considered equal to the one of its weakest link.

The HRO model, however, introduces uncertainty at the organizational level, creating spaces, building relationships of trust with the public and among groups of individuals who participate in it. La Porte (2001) [3] defines the characteristics that distinguish H.R.O calls (High Reliability Organizations): a) a flexible use of the notion of authority and a specific organizational structure for crisis situations; b) the active recognition, at all levels, skills, workers and their dedication to the task; c) the continuing training efforts; d) the existence of a system that rewards error detection and enhances the transmission and sharing of information about; e) the presence of attitudes which favor or hinder technical or organizational change, according to the positive judgments or negative effects that occur in organizational reliability.

Finally, artisanal models are based on processes of self regulation (Reynaud, 1988) [4] and the distinction of two dimensions in the organization of work. The first is the formal organization, based on a technique and efficiency logic. It is the logic that comes from management, technical management of production and from those who standardize the production processes. The technical logic is a control logic that seeks to resolve the external constraints of the organization: production, deadlines, product quality, among others. The second is the informal organization, the prevailing feelings and values. This is the logic of workers expressed in their daily work. The logic of feelings is a logic that seeks to resolve conflicts between internal values: it is a form of regulation that is opposed to formal regulations and affirms the autonomy of workers against attempts at control by technical and hierarchs. 
From this perspective, in an organization there are always two sources of regulation: autonomous regulation and control regulation. Control regulation is formal and explicit, targeted through technical and rational criteria. The autonomous regulation, for its part, although informal, is not spontaneous. It is an elaborate regulation, shared by workers, taught to new members and imposed on those who do not accept it. This form of regulation is also rational; through it the workers can accept technical rationality of production and efficiency. Affective values that workers embody in the autonomous regulation are not explained by the rational-emotional opposition, but by the power struggles linked to the meeting of the two forms of regulation.

The relationship between the three models and its forms of regulation is summarized in Figure 1.

Outlined security models guide the study of a specific case of the Uruguayan labor reality. The paper company analyzed was founded in 1898. It was originally established with Uruguayan capital, but since 2007 it belongs to a forest industry group with operations in Argentina and Uruguay. Unlike what happens with other competitors in the industry, this company is the only one that integrates into its work process from the planting of eucalyptus trees, the harvesting, the bucking of timber and pulp production, to the processing for paper processing and trading. In this research, the main interest lies in the industrial phase of the process that extends from the bucking of wood to paper production.

\section{2) Research methodology}

In the fieldwork of this research a qualitative methodological approach was implemented. The research design was opened, including the possibility that information that had not been covered since the start could appear. The flexibility of the design was guided by research objectives and intended to be adapted to the context of discovery in which is immersed the proper understanding of the phenomenon analyzed, based on the information that was emerging from the research process.

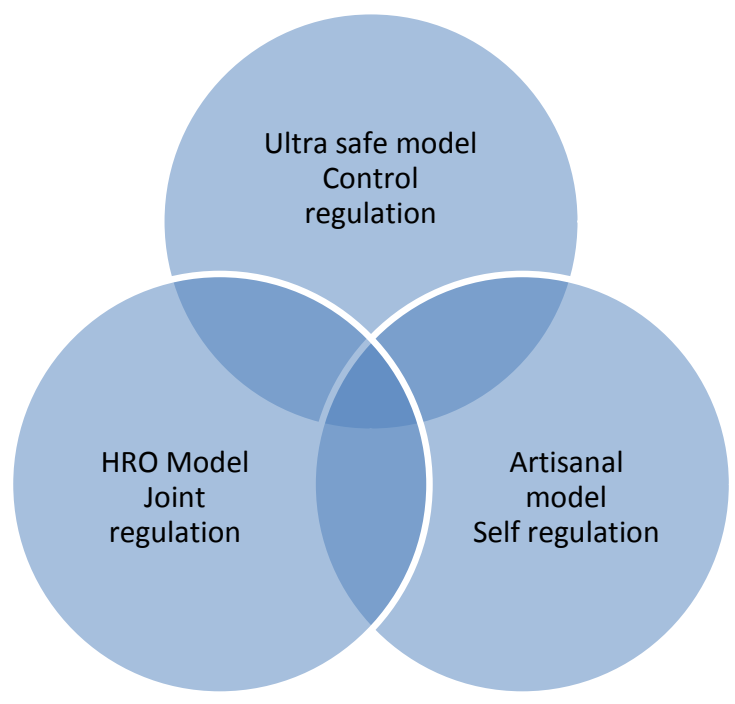

Figure 1. Security models and regulation. Prepared. 
The data collection technique was primarily based on the performance of semistructured individual interviews aimed at a sample of workers from different positions and areas. In this sense, a minimal pattern was established to guide the conversation interview, allowing freedom to delve into topics or issues that could emerge and could be considered relevant to the understanding of the research problem The researcher had a number of issues-questions for the interview, but could decide of the pertinence of the inclusion of a topic or question that had not been previously contemplated, as well as the order of introduction of various subjects in the conversation.

The analysis was performed from the construction of theoretical categories that guided the selection of the paragraphs of the interviews and allowed their grouping according to the direction given by respondents.

The strategy of approach to field work, given the size of the company and the multiplicity of work processes in it, began with a first exploratory interview to the management to determine the characteristics of the company and the various sectors and working processes. In addition, a sampling of interviews was conducted at two levels: by sector and according to the characteristics of workers (hierarchical level, seniority, gender). A total of 67 interviews were conducted between the months of June and October 2013. In the text we chose not to make direct quotations, due to the limits of extension thereof; but the whole description and analysis of the risk management process is based on the opinions gathered in these interviews.

\section{3) Human resources management.}

Security models are embedded in organizational structures that have their operating logic and specific ways of managing human resources in Figure 2. As Pichault and Nizet (2000) [5] argue, the policies of human resource management depend on the specific configurations found in organizations. These settings, following the classical work of Mintzberg (1983), [6] involve ways to organize and operate established contingently in companies or institutions, according to different dimensions: the role of different sectors of the organization, the forms of coordination of the activity, the design parameters, the

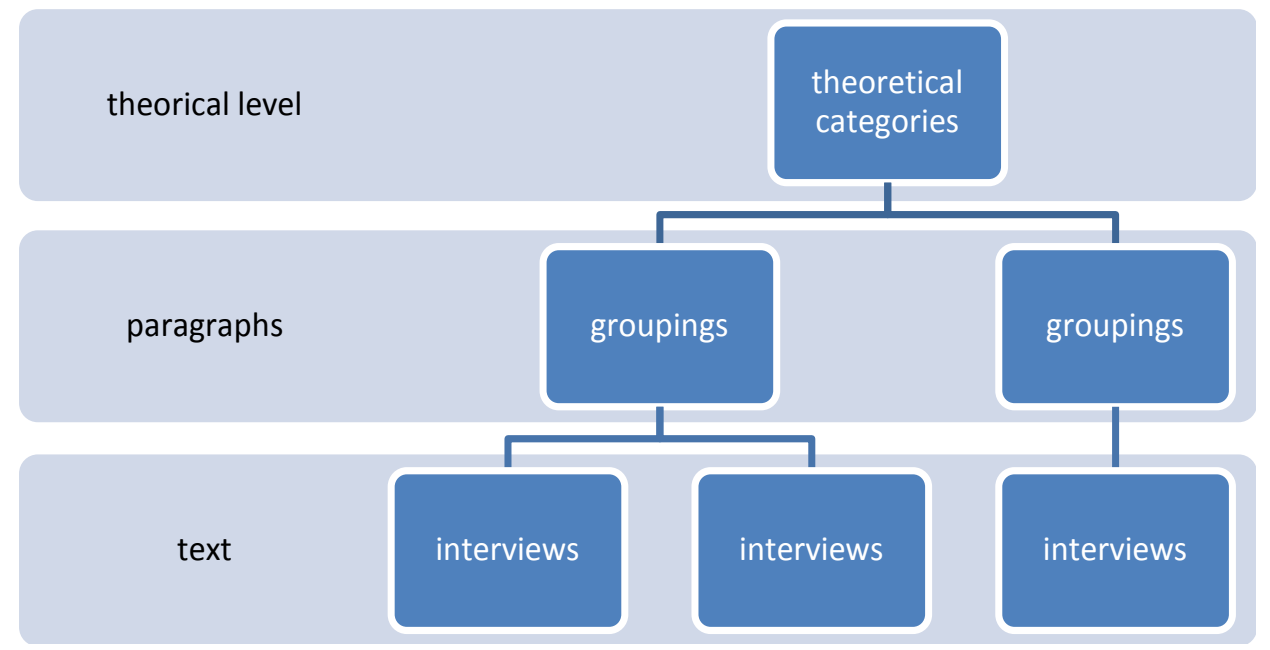

Figure 2. Flow block diagram. Prepared. 
relationships with the environment, among others. Among the types of configuration that Mintzbergraises, the one which is closest to the company studied is called bureaucratic machinelike. This configuration is characterized by carrying out a strong standardization of procedures through analysis tools of the worker's operations, job description and development of standards of behavior linked to these positions. In this configuration, the predominant force efficiency is derived from the standardization of processes. These organizations are stable and tend to thrive in environments that do not generate strong uncertainties; they have strong resistance to change and difficulty to adapt to varied and complex demands. Power relations, in turn, pass through the hierarchical control mechanisms on the basis of respect of the rules of procedure and of pre-planning activity.

The organizational design of the paper company analyzed is strongly associated with this configuration, although its conformation shows more attenuated features than those indicated by Mintzberg. The standardization process is relative, because it maintains strong craft components; the rules are very lax and personal relationships remain a considerable weight in the daily functioning of the organization. In that sense, although the bureaucratic form is the predominant machinelike, the company also combines features that Mintzberg called enterprise configuration, characterized by greater informality and a more personalized style of relationships.

Pichault and Nizet, in turn, develop different models of human resource management associated with the type defined by Mintzberg. The "objectifying" model is associated with the machine configuration described above. Social relations, in this model, are regulated according to impersonal criteria applied universally to all members of the organization. The culture associated with the "objectifying" model enhances respect for hierarchical authority and application of the rule in exchange of the protection provided to the members. Standards have a protection component to the extent that they preserve the workers from arbitrariness and favoritism from heads. Careers are built around impersonal rules respected by all: seniority, competitions or educational diplomas. In this model, working time is clearly established and differentiated from leisure time, and any extra effort should be rewarded by the organization

The human resource management style of the company analyzed, combines elements of the "objectifying" model outlined above, with elements of the "arbitrary" model, which Pichault and Nizet associate with business configuration. In this latter type of management, authority is more personalized, evaluations are conducted informally and intuitively, while organizational culture is focused on the identification with the company.

Human resource management is carried out within the framework of a specific conformation of its workforce which consists of a team of predominantly male workers (except in the areas of termination and administration), with a low educational level, mostly day laborers. The predominance of the male profile is associated with the job characteristics, mainly industrial, which in Uruguay has been traditionally mostly performed by men. However, the company has also hired women, specifically in the area 
of termination, performing tasks that require more concentration and dexterity, skills usually associated with female profiles.

Company workers have low rating in terms of formal education. Most workers (especially younger adults) have achieved the primary level of schooling and in some cases, some levels of secondary education. A few workers have been hired for their training or specific trade, mainly in the maintenance area (welder, mechanic, electrician). There are cases of training occurring during work mainly in administrative sector or for preventers concerning technical issues through short courses related to fire prevention, first aid or management of some specific technology. While conducting courses among workers does not seem to be frequent, qualification and skills acquired by experience in the factory have a central place in the company, because the technology used is obsolete and there are no courses or training available.

In terms of age, there is a significant generation gap in the company, linked to the age of the workers within the company. In this sense, there are two large groups: young workers (up to 30 years approximately) and other workers with more seniority and experience, in some cases they have been working for more than 20 years in the company: younger workers occupy lower-ranking positions whereas senior workers occupy positions of drivers or managers. In addition, the latter, according to testimonies collected in interviews bear the responsibility to teach and train younger workers for the tasks inherent to their positions in the overall functioning of the company. Finally, this differentiation among workers is noticeable, and introduces generational tensions associated with the legitimization of knowledge and experience among workers with more and less seniority which will be analyzed later.

The development of careers, in turn, is characterized by promotion according to seniority and experience of each employee within the company. Also, personnel selection is based on the recommendation of acquaintances, especially on the relationship workers have with each other (family, neighbors, etc.). For senior positions and technical specialization, selection and induction process is more complex and more professional. For middle management positions, however, the prevailing regime is the promotion by seniority. This form of construction combines career, as we saw above, universal criteria and proper objectives of the mechanistic model, subjective and arbitrary components proper of the business model.

With regard to stability in employment, human resources management in recent times was geared to promote early retirements, layoffs and redeployment of posts and tasks. This led to feelings and perceptions of uncertainty about the future employment of workers as well as about the future of the company. For obvious reasons such perceptions are more dramatic among older workers, because of the difficulties that reintegrating into the labor market represent for them. In this context, the company faces a crucial production continuity problem: breaking the chain of transmission of knowledge due to high staff turnover, retirements and withdrawals of better trained staff and age differences between more experienced people and young people.

Training difficulties are especially important for the company because it is one of the 
few places in the country where workers and engineers can be formed in the process of paper production. The possibilities of hiring workers from other firms or to quickly retrain experienced workers for different phases of the production process are reduced due to the specificity of the production process and the absence of alternative spaces for vocational training in this field. This problem requires the shortening of the learning process of workers to account for the demands of production, which is negative for the successful conclusion of the training processes and the training. As for safety training the situation is similar and follows the same paths as technical training: learning situations of risk comes through direct experience in close contact with senior workers. An example of this type of learning is the emergency stops, which are held in case of risk in the work process. Tensions arise because these training processes in the field of safety depend on a direct link established with another more experienced or senior worker, and are marked by personal relationships, spanning the weight of organizational standards and deriving in a source of conflict on hierarchical and generational terms.

Another dimension of training has to do with the internal management processes of knowledge. The monopoly of knowledge is a source of power, particularly in production systems formed by knowledge of the trades. In highly computerized processes, judicial notice is incorporated into the computer system and workers are more substitutable as new employees can be quickly incorporated in the established routines in the system. In the company analyzed, much of the production is computerized and processed through numerical control tools, although this did not necessarily imply replacement of office workers by worker strained in handling industrial software. The operators of this technology are workers with long experience in the company, who retrained and learned how to use the computer equipment.

The introduction of data-processing partly mitigates the problem of transmission of knowledge, to the extent that it allows registration knowledge and circulation through the tool. However, it does not solve it entirely. The production process of the analyzed company requires craft skills in many sectors to compensate or complement the operation of computer equipment, which allows difficulties in knowledge transmission persist. In this regard, interviews with workers indicate different situations, which are strongly associated with the positions of respondents in the hierarchical structure. From the perspective of leaders and managers, information and knowledge are transmitted fluidly between the experienced staff and the young workers. The latter, however, indicate that workers with more seniority keep knowledge for themselves and don't share it with the younger ones, as a mechanism to maintain distance and hierarchy. The survey indicates that knowledge management in the paper company is undermined by generational tensions, something which is clearly linked to the development of internal careers within the company. These tensions are part of the safety culture of the company, and are expressed in autonomous processes of risk regulation, as discussed below.

\section{4) The safety management}

In previous years, the company had an active security policy, with the presence of managers and technicians who developed preventers and regulatory actions of preven- 
tion and risk reduction. The development of these security policies was associated with the era of economic prosperity of the company, in the context of state protection of national industry and industrial production subsidies. This bright past collides with the present reality of the factory, where the security issue was pushed into the background because of economic difficulties, which is not consistent with the development in recent years of multiple standards of occupational safety taking place in the country.

This abandonment of security policies is perceived by workers through different dimensions. One of the problems mentioned is linked to the machine design. The daily operation thereof generates risks of different types for the health of workers such as excess pressure, spills or hazardous downloads. Another important aspect in relation to security dimension is the permanent tension between the maintenance area and the production area. The lack of building maintenance is perceived as a key factor in the frequency of occupational hazards because technology is obsolete and even when recently incorporated it still lacks security, prevention or proper maintenance. The old equipment, on the other hand, undergoes continuous breaks which highlight two crucial problems related to security issues. The first has to do with the lack of necessary maintenance resources to repair the machines. The second refers to an issue of strategic decision: the reluctance of the management to stop the machines and hence production, essential requirement to repair or rebuild the machine. These decisions are clear indicators of the priority given to production in the organizational culture of the company.

Not only does machinery for production show different problems related to security. The same situation applies to the electrical installation of the factory, which does not often offer the necessary protection elements, or is already damaged by time and use. In recent times, the company has also lost operational staff of experienced workers, especially in the maintenance area, due to the competition organized by other industries in the paper chain offering better pay conditions to the workers, or by way of retrenchment through early retirement. This bleeding drained the wealth of operational knowledge from the areas of production, constituting a source of disagreement and uncertainty, as above noticed. Despite the fact that recent recruitments were made, workers are young and do not have enough experience to carry out the job in the most appropriate manner.

In this context, the company developed a strategy for the transfer of responsibility for maintenance to workers who operate on a daily basis with the machinery. Moreover, it is also noticed that supervisors often perform maintenance tasks that belong to operators. This policy of the company generated strong resistance among workers, by increasing the burden of daily work without salary compensation. The increased workload in a context in which wages are better paid in other paper companies ends up exacerbating the problem of lack of qualified personnel, not only concerning maintenance but also in other sectors of production. Moreover, this transfer of responsibilities operates as a vehicle to remove the problem of security from business management and to transfer responsibility on the labor collective according to their knowledge and skills. 
Workers also perceive the absence of strong leadership related to safety matters, from the board of management and from corporate responsibility. As Andriessen (1978) [7] points out, these leaderships tend to have a positive contagion effect at lower levels of command, and their absence is felt in the daily operation of the company. This factor also operates indirectly on the transfer of responsibilities concerning safety matters towards direct operators' actions.

\section{5) The normalization of deviation}

The predominant model of security in the company throughout its history can be characterized as ultra-safe, following the classification of Amalberti outlined above. The bet is focused on the development of standards and procedures through which work processes increase security levels for direct operators, who must adhere to monitor compliance to the rules. This security models more easily coupled to an organizational configuration of mechanical type, in the sense of Mintzberg, The management style is the "objectifying" human resources according to the classification of Pichault and Nizet, standards for which the weight of regulations and operating rules is the basis of coordination of the whole system.

At this level, the company still has a set of standards and security protocols to prevent accidents. It also provides permanent personal protection to workers. Despite these efforts, security problems persist because these standards are actually violated on a daily basis by workers and production managers. As Bourrier indicated (2001) [8] standardization of diversion occurs when the transgression of important safety rules is not only widely known but also tolerated and accepted by peers and hierarchy. The tension between economic pressures and safety requirements favors this process; actors manage this tension usually deviating from certain safety standards because they believe that their strict application is negative for the economic performance of the company.

In the case of the company under analysis, normalization of deviation is a permanent practice of the organization. An example of the normalization of deviation can be found in the rules regarding the use of personal protection. The elements of protection used by workers of the company are: helmet, sunglasses, goggles, masks, earmuffs, gloves, vests, masks, protective shoes. This diversity of personal protection equipment is provided free of charge by the company to workers. Wearing a helmet and glasses is more widespread than the use of other personal protection. This is because the control mechanisms from the security office to line managers are aimed first and foremost at penalizing the lack of helmet use and lenses. The use of other personal protection depends on the specific productive activities performed by workers. Despite the availability of personal protection, their use is not widespread. The reasons for these behaviors are found in different sources of normalization of diversion presented in the company.

One of the causes of normalization of deviation occurs, following Boissières (2011), [9] where formal rules and safety procedures are established without consulting those who will use them. In these cases, it is likely that supervisors and employees are transgressing those rules and consider it normal in order to be able to continue doing their 
job. In the case of the paper company, safety standards were discussed, in the past, with delegates from safety committees, distributed in different productive sectors. When those safety committees shut down, discussion spaces disappeared and safety standards became perceived as business enforcement, preventing the worker's support.

A tense social climate also fosters the standard deviation, because supervisors do not insist too much on the application of safety procedures to avoid creating a greater discontent and to maintain the necessary cooperation to achieve production targets (Boissières, 2011). At this level, out of 350 workers in the company, about 40 are supervisors or heads, 7 of whom are engineers, most of them young people. The other supervisors are workers with a long experience within the company, promoted primarily by seniority. According to what is apparent from the interviews, there are many tensions between workers and supervisors.

One of them defines the competition existing between the heads in order to achieve the highest levels of production, as a constant pressure on workers. This competition leaves the security issue relegated to the background, due to the priority given to the increase of production. Another source of tension is the permanent rotation of the headquarters and the bleeding of managerial cadres, creating a strong loss of knowledge and management skills in the institution. This bleeding is perceived by the workers as a result of the high demands from supervisors, which leads them to seek other opportunities inless demanding companies.

The interviews highlight in some cases the arbitrariness of management when making decisions concerning the work process. These attitudes are also a source of mistrust that favors the process of normalization of deviation. As the rules and directives about work are continuously and arbitrarily changed, the legitimacy of standards in general and safety standards in particular erodes continuously, so respect tends to decay. Moreover, any initiative for change or criticism of this attitude faces strong corporate resistance from senior officers. The difficulties of creating dialogue and the lack of transparency in the hierarchical relationships are factors that tend to deepen the process of normalization of diversion.

Hierarchical tensions are often confused with generational tensions because of the age structure and forms of promotion mentioned above: age and seniority are determining factors in the development of career and the possibility to accede to higher charges. At that level, from the perception of the heads young people show a lack of respect for authority. This lack of respect for authority can be associated with all the problems of legitimacy in the relationship of authority manifested in the hierarchical relationships of the company. One way of expressing this rebellion and disagreement with the controls is the resistance to use personal protective element as a concrete expression of the normalization of deviation produced by the different strains mentioned.

For their part, young people accuse the leaders of not recognizing their knowledge and their abilities, and impeding their career within the company. The mechanism used to hinder the promotion of young people is to qualify them as "troublesome", which creates an environment of distrust regarding their career prospects. These generational 
differences transiting various aspects of the world of work are also reflected in the attitude towards safety. In this sense, young people perceive senior workers as workers who have their "own little ways" and in some cases are reluctant to take security measures. As noted by De la Garza and Poy (2009) [10] "little ways" of workers reflect the experience as a distinctive feature of the culture of trade, aimed at improving safety through the breach of the rules and procedures so to account for the mismatch between safety and production. In this sense, the perception of young workers denounces standardization processes of diversion occurring at all the levels of the hierarchical chain.

\section{6) Joint regulation and self-regulation}

The crisis of legitimacy of the rules underpinning the ultra-security model that the company has traditionally cultivated, and the increasing transfer of responsibilities aspects of this subject to workers, foregrounds the importance of the processes of self regulation (Reynaud, 1988) as the central mechanism of risk management in the company analyzed. This centrality is reinforced by the recent failure in attempting a joint regulation between management and union.

The first attempt of joint regulation was hiring a former production operator in charge of the safety area, following an agreement between the board of management and the union. In this context, the new manager developed strategies for prevention and control of security, which included policies focused on the protection of workers as well as policies focused on preventive maintenance of the physical plant (order, cleanliness, mechanical maintenance, signaling devices, safety of machinery and equipment). This agreement did not fructify due to the resignation of the manager because of the differences existing with the board of management regarding these issues, leaving the security area.

The delegate did not have strong backing among the workers themselves. One of the causes of this lack of support is linked to the cessation of operation of the health and safety committee in the company; this commission is bipartite and is endorsed by the legal rules developed since 2005 . While its operation is required by law, economic difficulties and labor policies of the company aimed at downsizing the plant in order to reduce costs, which led to the dismantling of this commission by the management mainly concerned with the production, and by the trade unions, whose strategies were aimed at the defense of jobs.

Another cause for this lack of support is the absence of real operation given to the figure of the safety representative worker which has also been regulated since 2005 . While workers made attempts to appoint workers' safety delegates by sector, no agreement was achieved with the company regarding the functions of this delegate. One of the most controversial points concerned the figure of the safety representative worker and whether he should have exclusive dedication to the subject or not. The company opposed resistance to the implementation of full-time, as production remained priority, while workers held the difficulties of engaging in both production and safety.

The second attempt for a joint regulation was the creation of the figure of the leader as a link in the chain of command between managers and workers. This figure aimed at 
enhancing the legitimacy of the controls and to iron out hierarchical tensions. The figure of the leader was created as an intermediate position between the head and the operator, making the link between the role of supervisor and worker. It emerged as a union proposal because the supervisors hired in recent years were young engineers who lacked the trust of the workers. However, the leader was a qualified worker, with long experience in the company and greater legitimacy over other workers than the new supervisors. While supervisors were once co-workers in the factory, engineers are seen as "newcomers", distant and with whom the workers do not establish trustful relationships. Leaders were also shaped as a link between the workers and the union, as the proposal had originated from the union of workers.

The experience of shaping the figure of the leader did not have the expected results. In some sectors, production managers resisted that figure, in other cases it was not clear what his functions were, or the selection criteria were unclear so they did not have enough legitimacy to develop their role. The formal appointment as leader does not necessarily mean that those who occupy this post have leadership skills. Contact with workers, organizational capacity and responsibility do not arise simply by appointment; in this sense, the people who occupied the post of leader not always embodied/met these features. Technical legitimacy problems also arose, to the extent that, in general, selected leaders did not always count with as much technical knowledge as the supervisors or the managers. While the figure of the leader generated some blurring in supervisory roles, the decisions of the supervisors always had more weight and support than the leader's.

The weakness of the mechanisms for technical regulation and the difficulties in achieving a joint regulation between management and union highlights the importance of independent regulation. Risk regulation rests on practical knowledge of the workers, acquired through their work experience and technical training. To the extent that the normalization of deviation becomes a permanent practice, safety is achieved through the adaptation of workers to risk and the autonomous construction of collective work.

An example of autonomous regulation is the refusal of workers to perform tasks which they perceive as risky under the conditions they are presented. The coordination of actions and notification of colleagues of the maneuvers are also part of these independent risk regulation processes. Another example of autonomous regulation is the concern for the safety of new workers, who do not know the work process. The experienced and craft workers take precautions in different maneuvers in the work process, beyond the established safety protocols. Individual care and self-protection are another dimensions related to self-regulation.

The independent risk regulation is also inserted into the hierarchical relationships, developing regulations that oppose the logic of control of the company. Within the rules that make up the autonomous regulation, the most important concern, as we saw above, is the refusal to perform hazardous tasks while the hierarch orders it. This rule creates tensions between workers and their hierarchy, weakening the construction of a collective knowledge through the exchange of knowledge among middle managers and 
operators to develop agreed security management strategies.

\section{Conclusions}

Risk management in the company under analysis is deployed in a production process with a weak taylorist matrix. The management is articulated with traditional type relationships and where there are spaces for the development of artisanal logic grounded in technical knowledge. While the organizational format originally structured from impersonal and universal objective standards, the management policies of human resources are based on a logic of arbitrary type, marked by discretion, distrust and the presence of strong tensions in hierarchical relationships. This management style prevents the building of trust and of integration spaces between managers and workers, which departs this case from the H.R.O. model discussed above.

Whereas the company has technically tried to regulate risk management through standards and procedures, they have a very weak legitimacy, so that the normalization of deviation becomes a permanent practice. In this context, security in the organization shifts to the ability of direct operators to be exposed and to continually adapt to situations of risk inherent to the work process in the organization; workers brings into play their practical experience and their knowledge of the craft acquired through practical learning. This form of risk management approaches the case studied to artisanal models defined by Amalberti, in which we found little safety regulation, which substantially depends on the qualities and skills of the operators.

Field observations indicate the dominant presence of a culture of trade as a mechanism for regulating the conduct of workers in relation to safety. Risk regulation that is built from the practice of workers is permeated by the logic of confrontation, in addition to the generational gaps and "fields" built by areas and work teams. This fragmentation widens the risk areas of the organization, and prevents its capitalization and its projection by the trade union of the company to develop alternative spaces of security management against the absence of efficient control regulations. Independent risk regulations also inserted into hierarchical relationships, developing regulations that oppose the logic of control of the company. On the other hand, there is a tendency from management to ignore the existing cultures of trade, expressed through personnel management policies which devalue the stock of constructed and accumulated knowledge gained through work experience. These policies are implemented in a context of constant overlapping human resource management tools, creating an environment of uncertainty not conducive to the development of forms of trust between workers and management, between hierarchies and operational level, between sectors and work teams, and between different generations of workers.

In this enclave, the union loses capacity for action in the field of oriented safety demands both preventive and reactive as it is focused on negotiating the impacts of new management policies for work and employment in the company. There is also little reflexivity by workers in relation to the components of their culture of trade. In fact, as this latter works, it is not made explicit by the group nor recognized as such in the con- 
text of tensions and powers between sectors and work teams, which shows the fragility of the safety management process in the company analyzed.

\section{References}

[1] Amalberti, R. (2013) Piloter la sécurité. Théories et pratiques sur les compromis et les arbitrages nécessaires. Springer-Verlag France, Paris.

[2] Dourlens, C., Galland, J.P. and Vidal-Naquet, P.A. (1991) Introduction. In: Dourlens, C., Galland, J.P., Theys, J. and Vidal-Naquet, P.A., Eds., Conquête de la sécurité, gestion des risques, 11-42 L'Harmattan, Paris.

[3] La Porte, T.R. (2001) Fiabilité et légitimité soutenable. In: Organiser la fiabilité. Sous la direction de M.Bourrier, 71-106. L'Harmattan, Paris.

[4] Reynaud, J.D. (1988) Les règles du jeu. L'action collective et la régulation sociale. París. A. Colin.

[5] Pichault, F. and Nizet, J. (2000) Les pratiques de gestion des ressources humaines. Collection Points Essais, Paris.

[6] Mintzberg, H. (1983) Power in and around Organizations. Prentice Hall, Englewood Cliffs.

[7] Andriessen, J. (1978) Safe Behavior and Safety Motivation. Journal of Occupational Accidents, 1, 363-376. http://dx.doi.org/10.1016/0376-6349(78)90006-8

[8] Bourrier, M. (2001) La fiabilité est une question d'organisation. In: Organiser la fiabilité. Sous la direction de Mathilde Bourrier. 9-38 L'Harmattan, París.

[9] Boissières, I. (2011) Groupe de travail "Leadership in Safety". Leadership en sécurité: Pratiques industrielles Numéro 2011-07 des Cahiers de la Sécurité Industrielle, Institut pour une Culture de Sécurité Industrielle, Toulouse. http://www.icsi-eu.org/francais/dev_cs/cahiers/

[10] De la Garza, C. and Poy, M. (2009) Segurança e Saúde Laboral, segurança industrial: Desafios de um enfoque de prevenção sustentável. RevistaLaboreal, 5, 94-104. http://laboreal.up.pt/pt/editions/volume-v--no1--07_2009/

Submit or recommend next manuscript to SCIRP and we will provide best service for you:

Accepting pre-submission inquiries through Email, Facebook, LinkedIn, Twitter, etc. A wide selection of journals (inclusive of 9 subjects, more than 200 journals)

Providing 24-hour high-quality service

User-friendly online submission system

Fair and swift peer-review system

Efficient typesetting and proofreading procedure

Display of the result of downloads and visits, as well as the number of cited articles

Maximum dissemination of your research work

Submit your manuscript at: http://papersubmission.scirp.org/

Or contact ojsst@scirp.org 